\title{
Study of Correlation of Hypertension and Anthropometric Measurements in Obese Vs Non - Obese Individuals
}

\author{
Sirikonda Aishwarya ${ }^{\circledR 1}$, Karankoti Raj Kumar ${ }^{\circledR 2}$, Rallabhandi Sai Sri Harsha ${ }^{\circledR 3}$, Patnala Chakradhar ${ }^{\circledR 4}$ \\ ${ }^{1}$ Assistant Professor, Department of General Medicine, Gandhi Medical College, Secunderabad, Telangana, India, 2Post Graduate, Department of General Medicine, \\ Gandhi Medical College, Secunderabad, Telangana, India, ${ }^{3}$ Intern, Department of General Medicine, Gandhi Medical College, Secunderabad, Telangana, India, \\ ${ }^{4}$ Associate Professor, Department of General Medicine, Prathima Institute of Medical Sciences, Nagunoor, Karimnagar, Telangana, India.
}

\section{Abstract}

Background: Obesity exists worldwide at a large incidence rate. All systolic and diastolic blood pressure show a strong association with the height and weight of both sexes. This research was intended to establish the incidence of hypertension in obese patients relative to findings reported in non-obese persons. The objective is to research Hypertension in accordance with the Body Mass Index and to equate it between the two classes of Obese and Non-Obese persons. Subjects and Methods: The following anthropometric tests were carried out of both such patients 1. Height 2. Weight 3. Circumference of dimension 4. The hip circumference. The Body Mass Index and the Waist Hip Ratio is determined from these measures. Blood pressure monitoring of BP was taken three times to validate systemic hypertension. Careful history was first taken of these cases involving pre-existing chronic hypertension and disease diagnosis. Results: The pre-hypertension level saw more people from both Obese and non-obese classes. Prevalence of stages 1 and 2 of hypertension was mostly seen in obese people. The mean systolic and diastolic blood pressure was higher in obese males than females but barely any noticeable variation in the waist circumference of $>100$ and in the waist circumference of 90-100 cm, males were greater than females. Conclusion: The incidence of elevated blood pressure and mean systolic and diastolic blood pressure in increased BMI classes, i.e. obese people, was far higher. High BMI demonstrated a strong hypertension association.

Keywords: BMI, Hypertension, Obese, Waist circumference, Hip circumference

Corresponding Author: Patnala Chakradhar, Associate Professor, Department of General Medicine, Prathima Institute of Medical Sciences, Nagunoor, Karimnagar, Telangana, India.

E-mail: drpatnalachakradhar@gmail.com

Received: 14 June $2020 \quad$ Revised: 01 August 2020

Accepted: 09 August 2020

Published: 26 December 2020

\section{Introduction}

Obesity is a persistent and highly widespread health problem that is marked by excess body fat. This grows slowly and sometimes continues for a lifetime. Overweight and obesity are an increasingly increasing challenge to healthier communities in a variety of countries and obese people. The global prevalence of obesity has risen considerably in recent decades. ${ }^{[1]}$ Obesity is growing as a big issue in India. Twentytwo million Indians are obese, particularly abdominal obese. Traditionally, obesity has been thought to be correlated with wealthier behaviors in Western nations. Obesity, though, is a fast-growing concern in developed nations and is now considered to be correlated with elevated health threats. Many research in India has found that improvements in eating habits, rates of physical activity, behaviors correlated with affluence and relocation to metropolitan areas are connected to a High chance of obesity including hypertension. ${ }^{[2]}$ The body mass index (BMI) is the most commonly accepted metric for assessing obesity which relies on obese medication criteria, with specific treatment termination points depending on the prevalence or lack of obese-related comorbid illness. ${ }^{[3]}$ In fact, often people with these metabolic conditions are either overweight or obese. Essential association 2 between BMI and metabolic disease is crucial to a deeper understanding of fundamental pathophysiological pathways contributing to an excess fat-related metabolic disorder. Some jurisdictions use the word overweight (rather than obese) to identify people with BMIs between 25 and 30 years of age. ${ }^{[4]}$ A BMI between 25 and 30 can be considered as medically relevant and deserving of clinical action, particularly in the face of risk factors that are affected by adiposity, such as hypertension. Large epidemiological research, ${ }^{[4,5]}$ The inverse association between BMI and mortality over BMI values of $25.0 \mathrm{~kg} / \mathrm{m} 2$ has been identified. Men and women with BMIs from 25.0 to $29.9 \mathrm{~kg} / \mathrm{m} 2$ are overweight and BMIs over $30.0 \mathrm{~kg} / \mathrm{m} 2$ are 
deemed obese. Obese persons are more likely than overweight to experience adverse impacts on health. Those guidelines for overweight and obese reflect the cut-off standards placed along the spectrum between the death rate and BMI.

\section{Subjects and Methods}

Source of Data a minimum of 200 Obese and 200 Non-Obese subjects between 20-50 years of age, who came to IP/OPD in the department of Medicine.

\section{Inclusion Criteria}

Both males and females more than 20 years of age including hypertension.

\section{Exclusion Criteria}

- Less than 20 years of age

- Pregnancy

- Patients on hypolipidemic drugs, diuretics, $\beta$ blockers

- Patient with the previous history of CAD

In all these patients the following anthropometric measurements are done 1. Height 2. Weight 3. Waist Circumference 4. Hip Circumference. From these measurements, Body Mass Index and waist-hip ratio were calculated. Blood pressure recording BP was taken three times to confirm systemic hypertension. Careful history was first taken in these patients regarding pre-existing systemic hypertension and about the treatment for the illnesses.

\section{Results}

Shows nearly identical distribution of BMI and Waist circumference in both men and women in obese situations per decade, although there was no statistically meaningful discrepancy ( $\mathrm{p}$-value $>0.05$ ).

Females were predominant in the $2^{\text {nd }}$ group of 30- 34.9 BMI, and there were a small number of participants in BMI > $35 \mathrm{~kg} / \mathrm{m} 2$ in both men and women.

There was hardly any significant difference between mean age and height among both obese and non-obese individuals. The Mean BMI, weight, Waist and hip circumference were more in the obese group.

$28 \%$ of the obese individuals had Systolic hypertension and $20 \%$ had diastolic hypertension. Only $12 \%$ in the non-obese group had Systolic hypertension and $7.5 \%$ had diastolic hypertension.

Prehypertension stage had more individuals from both Obese and non-obese groups. Prevalence of stage 1 and 2 of hypertension was mostly seen.
The mean Systolic and Diastolic blood pressure was more in obese males and females with hardly any significant difference with respect to a waist circumference of $>100$ and in 90$100 \mathrm{cms}$ waist circumference males were predominant than in females.

\section{Discussion}

Obesity and hypertension are directly linked to multifactorial diseases. Research of multiple demographic populations shows that hypertension occurrence in the obese community increases significantly. ${ }^{[6-9]}$ Hypertension in obesity is greater than non-obese and hypertension is higher in obese females than in males who are lean. It means that obesity in humans not only leads to the elevated prevalence of hypertension but also due to potential hereditary and environmental influences. Adult weight gain is usually a significant obstacle to eventual hypertension, although some studies have shown that weight loss in obesity often decreases blood pressure in the artery. ${ }^{[10-12]}$ Birth weight was also recommended for adult blood pressure, probably due to the association between birth weight and subsequent obesity. Hyperinsulinemia, obese tendency and insulin resistance have been shown to be responsible for the process of hypertension progression in obese individuals. This is known to help to reduce hypertension by activating the sympathetic nervous system and preserving sodium. Obesity and high blood pressure are the main risks of the cardiovascular system. The afterload of arterial hypertension to the left ventricle reduces, while stress raises the risk of stroke and preload. As a part of this double pressure, the heart adapts to abnormal left ventricular hypertrophy. Contractility is observed in early hypertension during obesity and ventricular ectopy. There is also a large risk of congestive heart failure and early mortality in obese hypertensive cases. Brown et al report-Four separate types of BMI (30.33 In NHANES III the age-based incidence of elevated blood pressure was 42 percent, respectively and 38 percent in obese men and women is classed as systolic $>$ $140 \mathrm{~mm} \mathrm{Hg}$, diastolic blood pressure $>90 \mathrm{~mm} \mathrm{Hg}$ or antihypertensive drugs). Such levels are twice as high in thin people and women (15 percent of both men and women) with hypertension prevalence. ${ }^{[13,14]}$ The incidence of hypertension often decreases with weight gain. The Framingham study revealed a $6.5-\mathrm{mm} \mathrm{Hg}$ blood pressure rise with an increasing $10 \%$ change in body weight, in the participants studied. ${ }^{[15]}$ Weight gain raises the frequency of hypertension even to rates not known to be a concern. This became apparent in a clinical survey by Nurses (Huang et al., 1998). In midlife, the increased risk for developing Hypertension became $60 \%$ greater among certain people with a weight increase at 18 years of age of as little as $5 \mathrm{~kg}$ compared to those whose weight had not risen more than $2 \mathrm{~kg} .{ }^{[16]}$ According to H. E. Bays et al SHIELD study showed that $80 \%$ of hypertensive patients were 
Table 1: Mean and standard deviation of BMI and waist circumference in each decade in both obese cases

\begin{tabular}{lllll}
\hline & MEAN BMI & \multicolumn{3}{l}{ Waist Circumference } \\
\hline Age Cases & Men & Women & Male & Female \\
\hline $\mathbf{2 0 - 3 0}$ & $29.921 \pm 3.6$ & $30.90 \pm 3.1$ & $105.5 \pm 10.1$ & $98.4 \pm 9.39$ \\
$\mathbf{3 0 - 4 0}$ & $30.78 \pm 3.35$ & $30.29 \pm 2.8$ & $104.8 \pm 9.23$ & $102.4 \pm 9.1$ \\
\hline $\mathbf{4 0 - 5 0}$ & $30.79 \pm 3.34$ & $31.08 \pm 3.04$ & $104.1 \pm 9.6$ & $106.2 \pm 13.01$ \\
\hline
\end{tabular}

Table 2: Distribution in Gender with respect to the class of obesity

\begin{tabular}{lll}
\hline BMI & Men & Women \\
$25-29.9$ (group 1 & 46 & 31 \\
$30-34.9$ (group 2) & 46 & 61 \\
$35-39.9$ (group 3) & 6 & 7 \\
$>40$ (group 4) & 2 & 1 \\
\hline
\end{tabular}

Table 3: Comparison between Obese and Non-Obese Demographic and Anthropometric Characteristics

\begin{tabular}{lll}
\hline Age & Obese & Non-Obese \\
Height & $35.96 \pm 8.9$ & $35.14 \pm 8.30$ \\
Weight & $164.82 \pm 6.96$ & $166.14 \pm 8.83$ \\
Bmi & $82.90 \pm 10.82$ & $59.11 \pm 6.85$ \\
Waist Circumference & $30.96 \pm 3.49$ & $21.45 \pm 1.81$ \\
Hip Circumference & $103.53 \pm 9.06$ & $80.02 \pm 5.06$ \\
\hline
\end{tabular}

Table 4: Prevalence of Hypertension in Obese and Non-Obese Individuals

\begin{tabular}{lllll}
\hline & Systolichtn & \% & Diastolichtn & $\%$ \\
Obese & 56 & $28 \%$ & 40 & $20 \%$ \\
Non - Obese & 24 & $12 \%$ & 15 & $7.5 \%$ \\
\hline
\end{tabular}

Table 5: Distribution of the Number of Subjects in Each BP Group Measured In Obese and Non - Obese Individuals

\begin{tabular}{lll}
\hline Blood Pressure & Obese & Non - Obese \\
$<120 / 80$ (Normal) & 24 & 74 \\
$120-139 / 80-89$ (Prehypertension) & 102 & 88 \\
$140-159 / 90-99$ (Stage 1) & 54 & 33 \\
$>160 />100$ (Stage 2) & 20 & 5 \\
\hline
\end{tabular}

Table 6: Difference in Systolic and Diastolic Blood Pressure Measurements Made In Obese and Non-Obese Individuals With Respect To Waist Circumference in Obese People

\begin{tabular}{|c|c|c|c|c|c|c|}
\hline \multicolumn{3}{|c|}{ Waist Circumference } & \multicolumn{2}{|l|}{ Obese } & \multicolumn{2}{|l|}{ Non - Obese } \\
\hline & & $\mathrm{N}$ & SBP & DBP & SBP & DBP \\
\hline \multirow[t]{2}{*}{ Male } & $<90$ & 8 & $124.4 \pm 14.8$ & $80.6 \pm 14.7$ & $117.2 \pm 11.1$ & $74.7 \pm 10.0$ \\
\hline & $>100$ & 77 & $138.4 \pm 12.3$ & $85.08 \pm 9.8$ & $129.3 \pm 12.1$ & $79.09 \pm 9.1$ \\
\hline \multirow[t]{2}{*}{ Female } & $<90$ & 9 & $125.1 \pm 16.0$ & $76.9 \pm 6.6$ & $117.9 \pm 15.7$ & $71.0 \pm 6.4$ \\
\hline & $>100$ & 54 & $138.08 \pm 12.4$ & $86.1 \pm 9.3$ & $127.6 \pm 11.5$ & $80.4 \pm 8.7$ \\
\hline
\end{tabular}


overweight or obese. ${ }^{[17]}$

\section{Conclusion}

In higher Bmi levels, the incidence of high blood pressure and mean systolic and diastolic blood pressure is decreased. A strong BMI has a strong connection with hypertension. In terms of anthropometric and blood pressure measurements, there was a rather statistically important gap between the obese and non-obese classes.

\section{References}

1. Ogden CL, Carroll MD, Curtin LR. Prevalence of overweight and obesity in the United States. 1999;

2. Flegal KM, Carroll MD, Kuczmarski RJ, Johnson CL. Overweight and obesity in the United States: prevalence and trends, 1960-1994. Int J Obes. 1998;22(1):39-47. Available from: https://dx.doi.org/10.1038/sj.ijo.0800541.

3. Flegal KM, Troiano RP. Changes in the distribution of body mass index of adults and children in the US population. Int $\mathrm{J}$ Obes. 2000;24(7):807-818. Available from: https://dx.doi.org/ 10.1038/sj.ijo.0801232.

4. Bhaskaran K, Dos-Santos-Silva I, Leon DA, Douglas IJ, Smeeth L. Association of BMI with overall and causespecific mortality: a population-based cohort study of 3.6 million adults in the UK. Lancet Diabetes Endocrinol. 2018;6(12):944-953. Available from: https://dx.doi.org/10. 1016/S2213-8587(18)30288-2.

5. Calle EE, Thun MJ, Petrelli JM, Rodriguez C, Heath CW. Body-Mass Index and Mortality in a Prospective Cohort of U.S. Adults. N Engl J Med. 1999;341(15):1097-1105. Available from: https://dx.doi.org/10.1056/nejm199910073411501.

6. Dustan HP. Hypertension and obesity. Prim Care. 1991;18:495-507.

7. Heyden S, Schneider KA. Obesity and hypertension: epidemiological aspects of the relationship. J Hum Hypertens . 1990;4(4):431-435.

8. Mikhail N, Golub MS, Tuck ML. Obesity and hypertension. Prog Cardiovasc Dis. 1999;42(1):39-58. Available from: https: //dx.doi.org/10.1016/s0033-0620(99)70008-3.

9. Kastarinen MJ, Nissinen AM, Vartiainen EA, Jousilahti PJ, Korhonen HJ, Puska PM, et al. Blood pressure levels and obesity trends in hypertensive and normotensive Finnish population from 1982 to 1997. J Hypertens. 2000;18(3):255262. Available from: https://dx.doi.org/10.1097/00004872-
200018030-00003.

10. Kaplan NM. Obesity in hypertension: effects on prognosis and treatment. J Hypertens Suppl. 1998;16(1):35-37.

11. Reisin E, Frohlich ED, Messerli FH, Dreslinski GR, Dunnfg, Jones MM, et al. Cardiovascular changes after weight reduction in obesity hypertension. Ann Intern. 1983;98(3):315-319. Available from: https://doi.org/10.7326/0003-4819-98-3-315.

12. Huang Z, Reddy A. Weight change, ideal weight and hypertension. Curr Opin Nephrol. 1999;8(3):343-346. Available from: https://dx.doi.org/10.1097/00041552-199905000-00011.

13. Nandeesha H. Atherogenic Lipid Risk Factors in Men Classified As Overweight and Obese. Indian J Physiol Pharmacol. 2008;52(2):205-208.

14. Hu D, Hannah J, Gray RS, Jablonski KA, Henderson JA, Robbins DC, et al. Effects of Obesity and Body Fat Distribution on Lipids and Lipoproteins in Nondiabetic American Indians: The Strong Heart Study. Obes Res. 2000;8(6):411-421. Available from: https://dx.doi.org/10.1038/oby.2000.51.

15. Kannel WB. The Relation of Adiposity to Blood Pressure and Development of Hypertension. Ann Intern Med . 1967;67(1):48-48. Available from: https://dx.doi.org/10.7326/ 0003-4819-67-1-48.

16. Huang Z, Willett WC, Manson JE. Body weight, weight change, and risk for hypertension in women. Ann Intern Med. 1998;128(2):81-88. Available from: https://doi.org/10.7326/ 0003-4819-128-2-199801150-00001.

17. Bays HE, Chapman RH, Grandy S. The relationship of body mass index to diabetes mellitus, hypertension and dyslipidemia: comparison of data from two national surveys: International journal of clinical Practice; 2007. Available from: https://doi. org/10.1111/j.1742-1241.2007.01336.x.

Copyright: (C) the author(s), 2020. It is an open-access article distributed under the terms of the Creative Commons Attribution License (CC BY 4.0), which permits authors to retain ownership of the copyright for their content, and allow anyone to download, reuse, reprint, modify, distribute and/or copy the content as long as the original authors and source are cited.

How to cite this article: Aishwarya S, Raj Kumar K, Sri Harsha RS, Chakradhar P. Study of Correlation of Hypertension and Anthropometric Measurements in Obese Vs Non - Obese Individuals. Acad. J Med. 2020;3(2):20-23.

DOI: dx.doi.org/10.47008/ajm.2020.3.2.5

Source of Support: Nil, Conflict of Interest: None declared. 